\title{
Upaya Guru Mengembangkan Karakter Peserta Didik Sekolah Dasar Melalui Pendidikan Ramah Anak
}

\author{
Wahyu Titis Kholifah \\ Pendidikan Guru Sekolah Dasar \\ Fakultas Keguruan dan Ilmu Pendidikan \\ Universitas Kristen Satya Wacana, Salatiga \\ Email :wtkholifah@gmail.com
}

\begin{abstract}
Abstrak
Karakter peserta didik yang terlihat belum diterapkan dengan baik di lingkungan sekolah, karakteristik peserta didik sangat penting untuk membentuk pribadi yang baik. Tujuan dari penelitian ini adalah untuk mengetahui pentingnya peran guru dalam mengembangkan karakter peserta didikdi sekolah dasar melalui pendidikan ramah anak. Metode penelitian ini menggunakan pendekatan deskriptif dan kualitatif yaitu untuk mendiskripsikan, menguraikan, dan menggambarkan upaya guru dalam mengembangkan karakteristik peserta didikdengan teknik pengumpulan data, observasi, dan wawancara. Hasil penelitian menunjukkan bahwa guru sudah baik dalam memahami karakter yang harus diterapkan kepada peserta didik, peran guru sangatlah penting dalam mengembangkan karakter peserta didik melalui kegiatan pembelajaran, pembiasaan, budaya sekolah, ekstrakurikuler dan visi misi sekolah.
\end{abstract}

Kata Kunci: Mengembangkan Karakter, Pendidikan Ramah Anak, Upaya Guru Mengembangkan Karakter

\begin{abstract}
The character of students who are seen as not being implemented well in the school environment, the characteristics of students is very important to form a good person. The purpose of this study was to determine the importance of the teacher's role in developing student character in primary schools through child-friendly education. This research method uses a descriptive and qualitative approach to described, spell out, and depict the efforts of teachers in developing the characteristics of students with data collection, observation, and interview techniques. The results showed that the teacher was good at understanding the characters that must be applied to students, the teacher's role was very important in developing the character of students through learning activities, habituation, school culture, extracurricular activities and vision and mission of the school.
\end{abstract}

Keywords: Developing Characters, Child Friendly Education, Teachers' Efforts to Develop Characters

\section{PENDAHULUAN}

Pada abad ke- 20 ini, peserta didik dituntut untuk memiliki nilai-nilai karakter meliputi komponen pengetahuan, kesadaran, kemauan, dan tindak lanjut dalam melaksanakan nilai-nilai tersebut, tetapi pada kenyataannya nilai-nilai karakter yang dituntut tidak terealisasikan dengan baik karena peserta didik belum dapat menerapkannya dalam kehidupan sehari-hari. Peran guru disini sangatlah penting dalam mendidik dan membentuk karakter peserta didik dalam dunia pendidikan agar nilai-nilai karakter yang dituntut dapat terealisasikan dalam kehidupan sehari-hari. Guru dapat memberikan 
pemantapan melalui materi dari aktivitas di lingkungan sekolah seperti budaya sekolah, pembiasaan, ekstrakurikuler, visi misi sekolah,dan lingkungan sekitar.

Undang-Undang Republik Indonesia Nomor 20 Tahun 2003 Tentang Sistem Pendidikan Nasional Bab I Pasal 1, menyebutkan bahwa pendidikan adalah usaha sadar dan terencana untuk mewujudkan suasana belajar dan proses pembelajaran agar peserta didik secara aktif mengembangkan potensi dirinya untuk memiliki kekuatan spiritual keagamaan, pengendalian diri, kepribadian, kecerdasar, akhlak mulia, serta keterampilan yang diperlukan dirinya, masyarakat, bangsa dan Negara. Sementara itu Tim Dosen FIP IKIP Malang (Sudarwan: 2015; Ichsan \& Bahrul, 2017). menyatakan bahwa pendidikan adalah proses potensi manusia yang mudah dipengaruhi oleh kebiasaan-kebiasaan yang baik, oleh alat (media) yang disusun sedemikian rupa, dan dikelola oleh mansuia untuk menolong orang lain atau dirinya sendiri dalam mencapai tujuan yang ditetapkan.Undang-Undang Republik Indonesia Nomor 20 Tahun 2003 Tentang Sistem Pendidikan Nasional Bab I Pasal 3, menyatakan bahwa pendidikan nasional berfungsi mengembangkan kemampuan dan membentuk watak serta peradaban bangsa yang bermartabat dalam rangka mencerdaskan kehidupan bangsa, bertujuan untuk berkembangnya potensi peserta didik agar menjadi manusia yang beriman dan bertakwa kepada Tuhan Yang Maha Esa, berakhlak mulia, sehat, berilmu, cakap, kreatif, mandiri, dan menjadi warga Negara yang demokratis serta bertanggung jawab. Dalam mengembangkan fungsi pendidikan nasioanl, peran pendidik (guru) sangat penting, seperti yang tertulis dalam UU RI No. 20 Tahun 2003 Tentang Sistem Sistem Pendidikan Nasional Bab I Pasal 3, bahwa pendidik adalah tenaga kependidikan yang berkualifikasi sebagai guru, dosen, konselor, pamong belajar, widyaiswara, tutor, instruktur, fasilitator, dan sebutan lain yang sesuai dengan kekhususannya, serta berpartisipasi dalam menyelenggarakan pendidikan. Menurut Mulyasa (2003: 100) (Kurniawan: 2015) guru merupakan tenaga profesional yang bertugas merencanakan dan melaksanakan proses pembelajaran, menilai hasil pembelajaran, melakukan pembimbingan dan pelatihan serta melakukan penelitian dan melakukan pengabdian kepada masyarakat terutama pada pendidik di perguruan tinggi.

Guru harus dapat mengajarkan, mendidik, dan melatih peserta didik di Indonesia agar menjadi anak yang berkarakter seperti tuntutan pendidikan saat ini. Jenis karakter yang hendak ditanamkan pada siswa, sebagaimana anjuran kementrian diknas, adalah: pertama, karakter cinta Tuhan dan segenap ciptaan-Nya; kedua, kemandirian dan bertanggungjawab; ketiga, kejujuran/amanah, diplomatis; keempat, hormat dan santun; kelima, dermawan, suka tolongmenolong dan gotong-royong/kerjasama; keenam, percaya diri dan pekerja keras; ketujuh, kepemimpinan dan keadilan; kedelapan, baik dan rendah hati, dan; kesembilan, karakter toleransi, kedamaian, dan kesatuan. (Jalil, 2012).Karakter mempunyai pengertian yaitu nilai-nilai perilaku manusia yang berhubungan dengan Tuhan Yang Maha Esa, diri sendiri, sesama manusia, lingkungan, dan kebangsaan yang terwujud dalam pikiran, sikap, perasaan, perkataan, dan perbuatan berdasarkan normanorma agama, hukum, tata krama, budaya, dan adat istiadat. (Ichsan \& Bahrul, 2017). Pendidikan karakter adalah suatu sistem penanaman nilai-nilai karakter kepada warga sekolah yang meliputi komponen pengetahuan, kesadaran atau kemauan, dan tindakan untuk melaksanakan nilai-nilai tersebut, baik terhadap Tuhan Yang Maha Esa (YME), diri sendiri, sesama, lingkungan, maupun kebangsaan sehingga menjadi manusia insan kamil.(Saifurrohman, 2014). Sedangkan menurut Lickona pengertian pendidikan karakter adalah suatu usaha yang disengaja untuk membantu seseorang sehingga ia dapat memahami, memperhatikan, dan melakukan nilai-nilai etika yang inti. (Lickona, 2006: 16).

Dapat disimpulkan bahwa pendidikan karakter adalah suatu usaha yang dapat dilakukan untuk memahami dan melakukan nilia-nilai etika seperti bersyukur terhadap Tuhan YME, diri sendiri, sesama, lingkungan dan bangsa. Dari hasil penelitian di SDN 4 Kotakarang, nilai-nilai pendidikan karakter mencakup dua tahap, yaitu perencanaan dan pelaksanaan. Perencanaan merupakan tahap awal dalam melaksanakan pendidikan karakter meliputi kegiatan sosialisasi perangkat kurikulum, perencanaan tata tertib sekolah dan siswa, serta pegarahan dari bagian kurikulum mengenai perencanaan nilai karakter melalui pembuatan Silabus dan RPP pada proses 
pembelajaran di kelas. Pelaksanaan nilai karakter diwujudkan melalui proses pembelajaran di kelas, pengondisian sekolah, kebiasaan dan budaya karakter untuk menanamkan nilai karakter positif pada siswa. (Siska, 2018).

Pendidikan karakter di sekolah dasar dapat dilakukan melalui pendidikan ramah anakuntuk memudahkan guru dalam mengajarkan nilai-nilai perilaku manusia. Menurut Arismantoro (2008) (Yulianto, 2016) yang dimaksud dengan pendidikan ramah anak adalah menciptakan lingkungan belajar yang kondusif (condusive learning community) sehingga anak dapat belajar dengan efektif di dalam suasana yang memberikan rasa aman, penghargaan tanpa ancaman, dan memberikan semangat. Sedangkan menurut (Yulianto, 2016) sendiri pendidikan ramah anak merupakan proses bagaimana seorang anak bisa bersemangat, antusias, dan berbahagia dalam mengikuti pelajaran dikelas, bukannya terbebani dan menjadikan belajar di sekolah sebagai momok yang menakutkan. Dengan begitu, mereka bisa mendapatkan pengetahuan dengan baik, mengikuti pembelajaran dengan nyaman dan aman (Yulianto, 2016). Seperti hasil penelitian di SDIT Nur Hidayah Surakarta, ketika ada seorang siswa yang meminta tolong baik kepada guru, pegawai harus dilayani dengan sepenuh hati tidak boleh membeda-bedakan. Sehingga siswa merasa nyaman dan tidak ada rasa takut sedikitpun karena pola interaksi yang dibangun dengan menggunakan pola kekeluargaan.

Menurut Machful Indra (Kurniawan, 2015) langkah-langkah yang dapat dilakukan untuk membentuk karakter siswa sekolah dasar antara lain sebagai berikut : 1 . Menentukan karakter: penentuan karakter dilakukan berdasarkan tujuan karakter yang diharapkan dalam artian setelah mengikuti seluruh proses pembelajaran, maka karakter yang terbentuk merupakan karakter yang sudah ditentukan. Penentuan karakter untuk siswa sekolah dasar hendaknya disesuaikan dengan karakteristik siswa sekolah dasar, misalnya karakter disiplin dan tanggung jawab. Karakter tersebut dikira tepat karena karakteristik anak sekolah dasar adalah senang bermain, bergerak, bekerja dalam kelompok; 2. Melaksanakan penanaman karakter: pelaksanaan penanaman karakter dilakukan melalui pembelajaran dengan cara mengintegrasikan karakter yang sudah ditentukan kedalam pembelajaran. Adapun pengintegrasian dapat dilakukan dengan cara, sebagai berikut: a) menentukan karakter dengan cara mengkaji standar kompetensi (SD) dan kompetensi Dasar (KD) pada standar isi (SI) yang didalamnya terkandung karakter yang ditanamkan. b) mengembangkan karakter yang terkandung dalam SK dan KD kedalam indikator. c) mencantumkan karakter dalam silabus dan rencana pelaksanaan pembelajaran; 3. Pembiasaan perilaku karakter: pembiasaan perilaku karakter akan membentuk karakter siswa seperti yang ditemukan oleh (Kurniawan, 2015) bahwa dalam pembentukan karakter, perlu adanya pembiasaan-pembiasaan yang dilakukan secara berulang-ulang dan konsisten. Berdasarkan hal tersebut dapat diartikan bahwa dalam membentuk peserta didik yang berkarakter pribadi yang baik maka dalam karakter yang ditanamkan harus dilakukan secara berulang-ulang. Misalnya, membentuk siswa yang berkarakter disiplin, karakter disiplin akan terbentuk apabila dilakukan secara berulang-ulang, sehingga peserta didik terbiasa dengan perilakuu disiplin. Perilaku disiplin yang dilakukan oleh siswa mengindikasikan bahwa pembentukan karakter peserta didik telah berhasil ditanamkan.

Selain langkah-langkah yang dapat dilakukan untuk membentuk karakter peserta didik, guru juga harus dapat mengkondisikan agar peserta didik lebih mudah dah nyaman dalam menerima apa yang diajarkan oleh guru.Menurut (Chabib Mustafa: 2009; Agus Yulianto: 2017) sebuah kawasan bisa dimasukan dalam kategori ramah anak apabila memiliki ciri-ciri sebagai berikut: 1) Anak terlibat dalam pengambilan keputusan tentang masa depan diri, keluarga, dan lingkungannya. Pemberian kesempatan yang terbuka misalkan dalam pengambilan keputusan tentang masa depan diri, keluarga, dan lingkunganya disertai dengan kepercayaan terhadap kemampuan anak merupakan sikap para guru yang sangat diharapkan. Tanpa sikap ini, perlengkapan sehebat apa pun yang disediakan disekolah tidak akan optimal dalam membantu perkembangan anak. Guru harus yakin pada kemampuan anak,keyakinan dan kepercayaan ini akan membuat sikapnya memberikan keleluasaan dan menempatkan anak sebagai subjek dan center pembelajaran. Jadi, anak akan terbantu untuk percaya pada diri dan kemampuannya, ia tidak akan ragu untuk 
mencoba dan mewujudkan keinginannya untuk bereksplorasi dan mengembangkan potensinya. 2) Kemudahan mendapatkan layanan dasar pendidikan, kesehatan dan layanan lain untuk tumbuh kembang.Melalui pendidikan inilah setiap orang belajar selurih hal yang belum diketahui. Melalui pendidikan akan lahir seorang yang berilmu. Sama halnya dengan kesehatan yang sangat penting untuk keberlangsungan hidup manusia. Dalam kaitanya dengan pengembangan kawasan ramah anak, maka seorang anak itu harus mendapatkan suatu pelayanan pendidikan dan kesehatan dengan mudah. Karena anak merupakan generasi yang meneruskan keberlangsungan kehidupan ini. 3) Adanya ruang terbuka untuk anak dapat berkumpul, bermain, dan berkreasi dengan sejawatnya dengan aman serta nyaman yang harus diperhatikan juga oleh pihak sekolah. Hal ini dilakukan untuk mengantisipasi kecelakaan yang dapat terjadi kapan saja, dan dimana saja, mengingat usia anak yang masih belum matang secara fisik dan mental dalam merencanakan dan mempergunakan tubuhnya. 4) Adanya aturan yang melindungi anak dari bentuk kekerasan dan eksploitasi.Kasus kekerasan yang sering terjadi harus menjadi perhatian penuh dalam dunia pendidikan. Hal ini dikarenakan, kasus kekerasan yang terjadi rata-rata pada usia anak-anak sekolah dasar, baik kekerasan seksual atau dikriminasi. Oleh karena itu, pihak sekolah harus benar-benar memperhatikan dan melindungi anak dari segala bentuk kekerasan dengan membuat peraturan serta kebijakan-kebijakan yang mendukung perlindungan anak. 5) Tidak adanya diskriminasi dalam hal apapun terkait suku, ras, agama, dan golongan.Sikap diskriminasi selayaknya tidak boleh terjadi dalam menciptakan kawasan ramah anak. Indonesia terdiri dari berbagai macam suku, ras, agama, dan berbagai golongan. Oleh karena itu, perlu adanya penanaman sikap saling menghormati dan menghargai satu sama lain yang tentunya dimulai dari seorang anakanak. Hal ini dapat dilakukan dalam kegiatan pembelajaran dan kehidupan sehari-hari. Dari ciri-ciri pendidikan ramah anak di atas dapat disimpulkan bahwa suatu pendidikan dapat dikatakan ramah anak apabila dengan melihat kondisi lingkungan belajar yang aman, nyaman, dan penuh kasih sayang di sekolah, hubungan yang terjalin dengan rasa cinta dan kasih sayang antara peserta didik dengan guru, orang tua, maupun sesama teman sebanyanya sangat berpengaruh dalam membentuk karakter seorang anak. (Yulianto, 2016). Sedangkan menurut Rohmawati dan Hangestiningsih (2019) sekolah ramah anak memiliki ciri-ciri sebagai berikut: (a) Perlakuan adil bagi murid laki-laki dan perempuan, (b) proses belajar dengan metode pembelajaran yang variatif sehingga siswa merasakan senang mengikuti pelajaran, (c) proses belajar mengajar didukung oleh media ajar, (d) murid dilibatkan dalam berbagai aktifitas yang mengembangkan kompetensi, (e) Murid dilibatkan dalam penataan kelas, (f) Murid dilibatkan dalam mengungkapkan gagasannya dalam menciptakan lingkungan sekolah (Kristanto, Khasanah, I., \& Karmila, M., 2011:47-48)

\section{METODOLOGI PENELITIAN}

Metode penelitian menggunakan pendekatan deskriptif dan kualitatif untuk mendiskripsikan, menguraikan, dan mengambarkan upaya guru dalam mengembangkan karakteristik peserta didik pada tuntutan pendidikan saat ini. Pendekatan kualitatif yaitu dengan menggunakan teknik pengumpulan data, observasi, dan wawancara.(Ichsan \& Bahrul, 2017). Pengumpulan data dalam penelitian ini dilakukan dengan menelusuri artikel-artikel secara online, penelusuran yang dilakukan menggunakan kata kunci "Pendidikan Ramah Anak", "Pendidikan Karakter", "Upaya Guru Mengembangkan Karakter Siswa" dan didapatkan beberapa artikel yang memenuhi kriteria yaitu adanya pembahasan tentang pendidikan ramah anak, pendidikan karakter, dan upaya guru dalam mengembangkan karakter siswa. Dari 11 artikel yang dipilih, terdapat 2 prosiding dan 9 jurnal ilmiah, yaitu :

1. Konsep Pendidikan Ramah Anak Dalam Membangun Karakter Siswa Kelas Rendah Di SD Muhammadiyah oleh Ichsan Anshory Dan Bahrul Ulum (2017).

2. Peran Guru Dalam Penerapan Sekolah Ramah Anak Di SD Muhammadiyah 16 Surakarta oleh Risal Septiyan Dwi Cahyono (2017).

3. Implementasi Pendidikan Ramah Anak Dalam Konteks Membangun Karakter Siswa Di Sekolah Dasar 
Negeri Di Kota Semarang oleh Senowarsito dan Arisul Ulumuddin.

4. Pendidikan Ramah Anak: Studi Kasus SDit Nur Hidayah Surakarta oleh Agus Yulianto (2016).

5. Karakter Pendidikan Untuk Membentuk Pendidikan Karakter oleh Abdul Jalil (2012).

6. Pendidikan Berbasis Karakter oleh Saifurrohman (2014).

7. Penguatan Pendidikan Karakter Bagi Siswa Sekolah Dasar Melalui Kearifan Lokal oleh Putri Rachmadyanti (2017).

8. Model Pendidikan Karakter Yang Baik (Studi Lintas Situs Bests Practices) Pendidikan Karakter di SD oleh Sa'dun Akbar Ahmad Samawi Muh. Arafiq Layli Hidayah.

9. Kajian Program Sekolah Ramah Anak Dalam Pembentukan Karakter Di Sekolah Dasar oleh Nuri Rohmawati, Endang Hangestiningsih (2019).

10. Implementasi Nilai Pendidikan Karakter Di Sekolah Dasar Negeri 4 Kotakarang Bandarlampung oleh Yulia Siska (2018).

11. Mendidik Untuk Membentuk Karakter Siswa Sekolah Dasar: Studi Analisis Tugas Guru Dalam Mendidik Siswa Berkarakter Pribadi Yang Baik oleh Machful Indra Kurniawan (2015).

\section{HASIL PENELITIAN DAN PEMBAHASAN}

Dari hasil penelitian pada beberapa jurnal, dapat disimpulkan bahwa peran guru dalam mengembangkan karakter peserta didik melalui pendidikan ramah anak sangat penting dalam membantu mengembangkan karakter peserta didik. Hal itu diwujudkan dengan berbagai indikator pendukung, seperti dari pemaparan visi dan misi sekolah, sarana dan prasarana yang mendukung, budaya sekolah, program ekstrakurikuler,pembelajaran pembiasaan, sarana bermain, minat bakat dan berbagai indikator yang lainnya.

Nilai-nilai kemanusiaan dituangkan ke dalam visi sekolah yang kemudian disosialisasikan kepada warga sekolah, mereka kemudian membangun komitmen bersama untuk mewujudkan visi. Berdasarkan pada visi tersebut kemudian disusunlah program kegiatan pembelajaran nilai dan karakter melalui berbagai kegiatan yang diselenggarakan di sekolah yakni melalui proses pembelajaran di kelas, kebiasaan di lingkungan sekolah, dan hal lainnya. Kegiatan yang dilakukan guru meliputi: 1) Guru selalu memberikan senyuman dan salam ketika bertemu peserta didik baik di lingkungan sekolah maupun luar sekolah. 2) Melakukan baris berbaris di depan kelas sebelum masuk kelas dan dipimpin oleh salah satu peserta didik, selalu mengucapkan salam dan berdoa ketika memulai dan mengakhiri pembelajaran, guru dapat menerapkan sikap tersenyum kepada peserta didik ketika sedang menjelaskan materi agar peserta didik nyaman dan tidak tertekan ketika pembelajaran berlangsung, terbuka kepada peserta didik ketika peserta didik ingin menanyakan materi yang belum ia pahami, menggunakan model pembelajaran yang inovatif dan kreatif agar peserta didik dapat berpartisipasi aktif dalam pembelajaran,dapat mengembangkan karakter tanggungjawab, tolong-menolong, kerjasama dengan orang lain dan menggunakan media (alat) yang nyata dalam pembelajaran. 3) Tidak melakukan tindakan kekerasan, diskriminasi, dan bullying, supaya anak dapat mengembangkan potensi yang dimiliki. 4) Seorang peserta didik yang meminta tolong baik kepada guru, pegawai harus dilayani dengan sepenuh hati dan jangan membedabedakan. 5) Fasilitas seperti ruang kelas dan laboratoium praktik juga baik sehingga akanmendukung proses implementasi nilai pendidikan karakter di sekolah. 6) Penyediaan sarana peribadatan, dan dilaksanakan kegiatankegiatan keagamaan yang relevan dengan visi agar dapat mengembangkan suasana dan karakter religius.7) Penyelenggaraan berbagai kegiatan ekstra kurikuler di satuan pendidikan dapat mengembangkan karakter baik, misalnya ektra kurikuler pramuka yang dapat mengembangkan karakter peserta didik menjadi berani, tanggung jawab, dapat bersosialisasi dengan baik, dapat bekerjasama dalam kelompok; ektra kurikuler menari, olahraga, PMR yang dapat mengembangkan minat bakat peserta didik. 8) Peranorang tua dan masyarakat juga dapat membantu dalam pengembangan karakteristik baik dan sebagai kontrol/pengendali karakter peserta didik.

\section{SIMPULAN}


Berdasarkan hasil penelitian upaya guru dalam mengembangkan karakter peserta didik melalui pendidikan ramah anak, peran guru sangat besar dalam mengembangkan karakteristik peserta didik di dunia pendidikan. Upaya yang dilakukan guru dapat dilaksanakan pada saat kegiatan pembelajaran di kelas; pembiasaan ketika berada di lingkungan sekolah dan luar sekolah;kegiatan ekstrakurikuler yang dapat mengembangkan minat bakat peserta didik, rasa tanggung jawab, berani, bersosialisasi dengan baik, dan bekerjasama dalam kelompok; mewujudkan dan menerapkan visi misi sekolah yang berhubungan dengan pengembangan karakter peserta didik. Maka penulis berharap guru Sekolah Dasar dapat menerapkan upaya-upaya tersebut agar peserta didik dapat menjadi pribadi yang berkarakter baik.

\section{DAFTAR PUSTAKA}

Cahyo, R. S. (2017). Peran Guru Dalam Penerapan Sekolah Ramah Anak Di Sd Muhammadiyah 16 Surakarta .

Ichsan, A., \& Bahrul, U. (n.d.). KONSEP PENDIDIKAN RAMAH ANAK DALAM MEMBANGUN KARAKTER SISWA KELAS RENDAH DI SD MUHAMMADIYAH. Prosiding SENASGABUD (Seminar Nasional Lembaga Kebudayaan), 78.

Jalil, A. (2012). Karakter Pendidikan untuk Membentuk Pendidikan Karakter Nadwa. Jurnal Pendidikan Islam Vol. 6, Nomor 2.

Kurniawan, M. I. (2015). MENDIDIK UNTUK MEMBENTUK KARAKTER SISWA SEKOLAH DASAR: Studi Analisis Tugas guru Dalam Mendidik Siswa berkarakter Pribadi yang Baik. JURNAL PEDAGOGIA ISSN 2089-3833 Volume. 4 No. 2.

Nuri , R., \& Endang , H. (2017). Kajian Program Sekolah Ramah Anak Dalam Pembentukan Karakter Di Sekolah Dasar Prosiding Seminar Nasional PGSD.
Rachmadyanti, P. (2017). PENGUATAN PENDIDIKAN KARAKTER BAGI SISWA SEKOLAH DASAR MELALUI KEARIFAN LOKAL. JPSD Vol. 3 No. 2, 204.

Sa'dun, A., Ahmad, S., Muh., A., \& Layli , H. (2014). MODEL PENDIDIKAN KARAKTER YANG BAIK (STUDI LINTAS SITUS BESTS PRACTICES) PENDIDIKAN KARAKTER DI SD.

Saifurrohman. (2014). PENDIDIKAN BERBASIS KARAKTER. Jurnal Tarbawl Vol. II. No. 2., 48.

senowarsito, \& Arisul, U. (n.d.). IMPLESEMENTASI PENDIDIKAN RAMAH ANAK DALAM KONTEKS MEMBANGUN KARAKTER SISWA DI SEKOLAH DASAR NEGERI DI KOTA SEMARANG.

Siska, Y. (2018). MPLEMENTASI NILAI PENDIDIKAN KARAKTER DI SEKOLAH DASAR NEGERI 4 KOTAKARANG BANDARLAMPUNG. Prosiding Seminar dan Diskusi Nasional Pendidikan Dasar.

Yulianto, A. (2016). Pendidikan Ramah Anak: Studi Kasus SDIT Nur Hidayah Surakarta. Volume. 1, No. 2. 